AIAA-2003-4726

\title{
DIRECT DRIVE HALL THRUSTER SYSTEM DEVELOPMENT
}

\author{
W. Andrew Hoskins, ${ }^{*}$ Daniel Homiak ${ }^{\dagger}$ and R. Joseph Cassady ${ }^{\dagger}$ \\ Aerojet-General Corporation \\ Redmond, WA \\ Tom Kerslake, ${ }^{\S}$ Todd Peterson, ${ }^{\sharp}$ Dale Ferguson ${ }^{* *}$ and Dave Snyder
NASA Glenn Research Center
Cleveland, OH \\ Ioannis Mikellides ${ }^{\ddagger \ddagger}$ and Gary Jongeward ${ }^{\S \S}$ \\ Science Applications International Corporation \\ San Diego, CA \\ Todd Schneider, \\ NASA Marshal Space Flight Center \\ Hunstville, AL
}

\begin{abstract}
$\underline{\text { Abstract }}$
The status of development of a Direct Drive Hall Thruster System is presented. In the first part, a study of the impacts to spacecraft systems and mass benefits of a direct-drive architecture is reviewed. The study initially examines four cases of SPT-100 and BPT-4000 Hall thrusters used for north-south station keeping on an EXPRESS-like geosynchronous spacecraft and for primary propulsion for a Deep Space-1 based science spacecraft. The study is also extended the impact of direct drive on orbit raising for higher power geosynchronous spacecraft and on other deep space missions as a function of power and delta velocity. The major system considerations for accommodating a direct drive Hall thruster are discussed, including array regulation, system grounding, distribution of power to the spacecraft bus, and interactions between current-voltage characteristics for the arrays and thrusters. The mass benefit analysis shows that, for the initial cases, up to $42 \mathrm{~kg}$ of dry mass savings is attributable directly to changes in the propulsion hardware. When projected mass impacts of operating the arrays and the electric power system at $300 \mathrm{~V}$ are included, up to $63 \mathrm{~kg}$ is saved for the four initial cases. Adoption of high voltage lithium ion battery technology is projected to further improve these savings. Orbit raising of higher powered geosynchronous spacecraft, is the mission for which direct drive provides the most benefit, allowing higher efficiency electric orbit raising to be accomplished in a limited period of time, as well as nearly eliminating significant power processing heat rejection mass. The total increase in useful payload to orbit ranges up to $278 \mathrm{~kg}$ for a $25 \mathrm{~kW}$ spacecraft, launched from an Atlas IIA. For deep space missions, direct drive is found to be most applicable to higher power missions with delta velocities up to several $\mathrm{km} / \mathrm{s}$, typical of several Discovery-class missions. In the second part, the status of development of direct drive propulsion power electronics is presented. The core of this hardware is the heater-keeper-magnet supply being qualified for the BPT- 4000 by Aerojet. A breadboard propulsion power unit is in fabrication and is scheduled for delivery late in 2003.
\end{abstract}

\section{Introduction}

A three-year program ${ }^{1}$ to develop a Direct Drive Hall Thruster (D2HT) system as part of the NASA Advanced Cross-Enterprise Technology Development Initiative is entering its third year. This project builds from an early proof of concept test done in 1997 at NASA Glenn Research Center (GRC). ${ }^{2}$ The direct drive concept takes advantage of the natural similarity between the voltage source characteristics required to run a Hall thruster and those of a solar array. The intent is to eliminate significant portions of the Hall thruster power

\footnotetext{
Sr. Principal Development Engineer, Senior Member

'Electrical Enginecr

+Sr. Manager, Business Development, Separatist

Acrospace Engineer, Member

${ }^{\text {"Program Manager }}$

Copyright $(2003$ The American Institute of Aeronautics and Astronautics, Inc. All rights reserved.
}

processing in favor of a direct connection to save mass, complexity and cost. A key to the direct drive concept is the development of solar arrays from $300 \mathrm{~V}$ and up. High voltage array modeling ${ }^{3}$ and array-plasma interaction measurements ${ }^{4}$ complement the spacecraft system analysis and power electronics development presented here. This paper provides results to date for the system study and the status of development of direct drive propulsion power electronics at Aerojet.

\section{Program Scope}

The Direct Drive Hall Thruster Program was proposed

\footnotetext{
- Space Environments Group Leader

${ }^{\dagger+}$ Electrical Engincer

\# Sr. Staff Scientist, Mcmber

Program Manager

Physicist
} 
as an enhancement specifically for a Solar Electric Propulsion (SEP) system. The same load characteristics that make a direct drive Hall thruster feasible also allow for a direct drive architecture using ion engines. However, Hall thrusters are better suited to application to solar direct drive due to their lower inherent operating voltages. A BPT -4000 Hall thruster operates efficiently at only $300 \mathrm{~V}$, while the NSTAR ion engine typically runs at $1100 \mathrm{~V}$, which is much harder to achieve in the near term with a solar array. Even after normalizing by the equivalent voltage required for simple electrostatic acceleration of an ion:

$$
A=\frac{V}{V^{*}}=\frac{2 e V}{m_{X e} u_{+}^{2}}=\frac{2 e V}{m_{x e}\left(\left.g\right|_{s p}\right)^{2}}
$$

ion engines require about $25 \%$ more voltage to get the same specific impulse as Hall thrusters. While the direct drive team is conducting solar array modeling and tests up to $500 \mathrm{~V}$ and has taken preliminary data up to $2 \mathrm{kV}$, near-term application of direct drive SEP technology favors a Hall thruster and missions that do not require extremely high specific impulse.

Recently, initiatives to develop nuclear electric propulsion (NEP) systems have gained significant interest, including interest in direct drive or minimal conversion system configurations. Because of the differences in how the electricity is generated, possibly resulting in higher bus voltages for NEP, some barriers to accomplishing a direct drive ion engine may be reduced. In any case, the higher bus voltage permits higher specific impulse direct drive operation, opening up the NEP mission space to significantly different missions than a direct drive SEP system. In fact, direct drive or minimal conversion architecture can have very high leverage in high-powered NEP missions. Although analysis of NEP drive configurations is outside the scope of this project, many of the principles and system issues examined SEP direct drive have relevance to an NEP direct drive system.

\section{System Study}

\section{Overview}

The purpose of the system study is to identify issues and quantify benefits of a direct drive Hall thruster system, diagrammed in Figure 1. The system study assumptions and initial results are presented in detail in Reference 5. These results are summarized and extended here to include the impact of direct drive to orbit raising of geosynchronous satellites and higher power deep space missions.

While the primary focus is on the Hall thruster power train and operation, the direct drive configuration necessarily entails the use of a high voltage (e.g. 300 V) solar array on the spacecraft. Since this is a significantly higher voltage than standard spacecraft buses today (e.g. 35,70 or $100 \mathrm{~V}$ ), some provision must be made to transmit bus power to the spacecraft battery and non-propulsion power loads. If the impact of using a high voltage electric power system (EPS) is positive, the advantages to the spacecraft can be considered an added benefit of direct drive. If it is negative, then the disadvantages to the spacecraft must be weighed against the other benefits of a direct drive. Ongoing research indicates that there are benefits of higher spacecraft bus voltages, independent even of a direct drive propulsion system. ${ }^{5,7}$

\section{Reference Case Characteristics}

Four initial cases, involving two reference spacecraft and two Hall thruster designs that were chosen to correspond to existing plasma data and ongoing plasma interaction modeling, were studied for system impacts of direct drive. The parameters for these cases, are summarized in Table 1. The analysis was subsequently extended to higher power geosynchronous spacecraft and deep space missions.

\section{Spacecraft}

The iwo iniiiai reference spacecrafi were EXPRESS and Deep Space-1 (DS-1). As previously described, ${ }^{5}$ the EXPRESS spacecraft is a Russian built geosynchronous communications satellite, weighing $2600 \mathrm{~kg}$ on orbit and carrying eight SPT- 100 thrusters to perform station keeping only. A modified analog to EXPRESS was assumed for case 2 at $5000 \mathrm{~W}$ with a BPT-4000. The limited mass and power for the EXPRESS baseline, as well as the exclusion of Hall thruster orbit raising were expected to yield conservative results for the benefits of a direct drive system for the initial cases.

Geosynchronous spacecraft of up to $25 \mathrm{~kW}$ have been envisioned for the near future. ${ }^{8,9.10}$ A key additional aspect to these missions will be the use of the electric propulsion to perform some of the orbit raising. Typically, on board chemical propulsion would be used for at least part of the orbit raising, with electric propulsion taking the spacecraft the rest of the way to geosynchronous orbit. Since time is a key cost factor for getting the payload delivered to orbit, it is important for these missions to operate at a higher thrust. This favors a lower Hall thruster discharge voltage, making it easier to implement a direct drive approach. The combination of these factors makes this one of the most attractive applications for direct drive.

Deep Space-1 (DS-1) was the first of the NASA New Millennium spacecraft, designed to validate high risk, high payoff technologies. It carried a $30 \mathrm{~cm}$ xenon ion propulsion system for primary propulsion and had a BOL "wet" mass of $486 \mathrm{~kg}$. ${ }^{12}$ The baseline mission for DS-1 involved $1320 \mathrm{~m} / \mathrm{s}$ velocity change and the extended mission required $4400 \mathrm{~m} / \mathrm{s} .{ }^{13}$ Further details of the spacecraft are given in reference 5 and are summarized on Table 1 . Case 4 assumes a modified spacecraft with $5000 \mathrm{~W}$ of power carrying a BPT- -4000 . 
DS-1 is not unlike many deep space missions in the variation in array power and voltage with distance from the sun or in the relatively low payload power relative to the propulsion power. It is, however, relatively modest in terms of power and delta velocity. While the Near Earth Asteroid Rendezvous (NEAR) mission had only $1880 \mathrm{~W}$ of solar array power and a $1420 \mathrm{~m} / \mathrm{s}$ mission, ${ }^{14}$ missions now in development are looking at much higher power levels. Dawn ${ }^{15}$ is flying a $7.5 \mathrm{~kW}$ array and has a velocity increment of $\sim 10 \mathrm{~km} / \mathrm{s}$. Other candidate deep space missions include NEAR-type asteroid rendezvous, Mars rendezvous, and Venus rendezvous, ${ }^{16}$ which all have velocity increments under $5000 \mathrm{~m} / \mathrm{s}$.

\section{Hall Thrusters}

The SPT- $100^{17,18}$ and the BPT- $4000^{19}$ were chosen for the study because they are among the most mature and well-characterized thrusters, as well as being the subjects of the array-plume interaction modeling and test. Details of the thrusters and their performance were given previously. ${ }^{5}$ The US qualified version of the $1500 \mathrm{~W}$ SPT system has a Space Systems/Loral built power processing unit (PPU) that operates two redundant SPT-100s and has a mass of $8.3 \mathrm{~kg}$. The $5000 \mathrm{~W}$ BPT -4000 system pairs one dedicated PPU at a mass of $12.6 \mathrm{~kg}$ with each thruster. The nominal operating voltage of each thruster is $300 \mathrm{~V}$, although both can be operated over a range from 200 to $450 \mathrm{~V}$, providing specific impulses ranging from roughly 1000 to 2100 seconds.

Of interest is also the impact of direct drive operation at higher voltage and therefore higher specific impulses to make larger velocity increment missions feasible. High voltage Hall thruster data ${ }^{20}$ indicates that a similar nondimensional acceleration voltage, $\mathrm{A}$, can be maintained up to $800 \mathrm{~V}$ with a Hall thruster, providing up to 2770 $\mathrm{s}$ specific impulse. It is interesting to note that above $800 \mathrm{~V}$ the Hall thruster data shows no advantage over an ion engine in terms of specific impulse at a given voltage.

\section{Solar Array}

The reference solar array for these cases is a planar array built from Spectrolab triple junction GaInP2/GaAs/Ge cells. These cells are recent state of the art with $27 \%$ efficiency, ${ }^{21}$ and similar cells are used on the Boeing 702 and Lockheed $\mathrm{A} 2100^{\mathrm{TM}}$ bus, as well as in the Radiation Technology Demonstration spacecraft trade study, from which projected array specific powers were interpolated as a function of voltage. ${ }^{4}$ Details of the solar array design and performance assumptions were given previously.

\section{System Considerations}

The system schematic diagram in Figure 1 shows the major components of a direct drive system and their relationship to each other. An array is represented with two of what will be several parallel strings shown.

\section{Array Regulation}

Because of the relationship between voltage and current for a solar array and the desire to operate the array at reasonable performance levels under widely changing loads, some sort of array regulation is usually used for spacecraft powered with a solar array. For direct drive situation, Direct Energy Transfer (DET) regulation with shunts is clearly favored over a series mounted Peak Power Tracker (PPT) technique.

\section{System Grounding}

"System grounding" specifically refers to how the spacecraft chassis is connected to the solar array circuit. By its nature the chassis cannot be isolated from the plasma around the spacecraft. In addition, the array has widely different voltage surfaces potentially exposed to the plasma environment. Therefore, the electrical relationship between the spacecraft chassis and the array is critical.

The addition of a thruster cathode to the spacecraft system brings in a third point where the spacecraft electronics interact with the surrounding plasma. The cathode is designed to provide an extremely strong connection with the thruster plasma, just like a plasma contactor. In the direct drive configuration the transformer isolation between the thruster and the array is removed, by definition, connecting the negative side of the array to the plasma potential across the fall and coupling voltage. One implication of this is that the array will be held mostly positive with respect to space plasma regardless of how the chassis is connected. If the chassis is connected to a potential much above the negative side of the array, because it cannot be effectively isolated from the space plasma, it will simply collect large electron currents from the plasma. Therefore, the chassis must be connected at or near the negative side of the array.

\section{Bus Power Distribution}

Since direct drive architecture requires, by definition, an increase in array voltage well above standard bus voltages, it is necessary to consider how to provide power to the spacecraft bus. Four possible configurations were traded: high voltage bus, step down converter, tapped/dedicated arrays, and reconfigurable arrays.

While the most straightforward approach to accommodating a $300 \mathrm{~V}$ array is to run the bus at 300 $\mathrm{V}$ also, the optimum Power Management and Distribution (PMAD) configuration depends on the relative ratio of peak thruster power to peak spacecraft power. In the case of a geosynchronous spacecraft, where the full spacecraft power is used most of the time by the payload, step down conversion of the payload 
bus power merely shifts the conversion burden from the propulsion power system to the payload power system. The combination of added conversion mass and conversion inefficiency was shown to favor a high voltage payload bus over payload step down converter by 12 to $16 \mathrm{~kg}$ for EXPRESS cases 1 and $2 .^{5}$

The battery represents the most significant problem for the high voltage bus option, and its potential impact was the most difficult to assess. $300 \mathrm{~V}$ would require too many cells in series for $\mathrm{NiH} 2$ batteries. One option would be to use the battery charge and discharge regulators (Figure 1) to act as step converters for the battery only. For a regulated bus these already exist, but the batter discharge regulator needs to be able to provide full spacecraft power in eclipse. A second option that was investigated was migration to higher voltage lithium ion technology. A mass estimate indicated that, due to its higher energy density, such a migration could actually save significant additional mass relative to the baseline $\mathrm{NiH} 2$ batteries at lower voltage (see Table 2).

The study showed that the relatively small payload power requirement compared to thruster power on DS-1 would make a step down converter option more favorable for cases 3 and 4 . Due to the relatively small battery capacity requirements for DS- 1 , the potential advantage of high voltage $\mathrm{Li}$-ion batteries depends upon the availability of a smaller battery cell. For the purposes of the trade study, a step down converter was assumed.

Reconfigurable arrays were found to be inapplicable for DS- 1 cases since the bus loads and thruster must operate simultaneously. They added several $\mathrm{kg}$ of switching mass to geosynchronous missions, such as EXPRESS, while missing the savings due to a high voltage EPS. However, a form of this option could be enabling when orbit raising is considered since it would be advantageous to run orbit raising at low voltage and NSSK at high voltage at the thrusters. Further work is necessary on a detailed trade for this extended case.

Tapped or separate, dedicated arrays were ruled out for geosynchronous spacecraft due to the low duty cycle operation of the thruster. For DS-1 a fixed ratio between thruster and payload power was found to have a mass penalty greater than the step down converter to accommodate the reduction in array power with distance from the sun.

In summary, migration to a high voltage bus was recommended for geosynchronous missions and use of a payload power converter was recommended for deep space missions.

\section{I-V Source and Load Characteristics}

Current-Voltage (I-V) curves for two of the four initial cases in Figures 2 and 3 show steady state current and voltage characteristics of the arrays and the thrusters at constant flow rates. In addition, lines of constant thrust and constant specific impulse are shown for the thrusters. Note that the peak thrust condition is on the knee of the array curve just below the short circuit current. Peak specific impulse operation is actually somewhat below the knee on the open circuit leg, where the thruster should be very stable. Several potential source-load issues are highlighted by these curves, including stability near short circuit current, array voltage changes, dynamic system interactions, and thruster start up.

As long as the thruster is operating along the open circuit leg of the solar array I-V curve, the array/thruster source-load intersection is very stable. However, note the hump in current from 100 to $150 \mathrm{~V}$ in Figure 2. This low impedance region is generated by the relationship between ionization and the full development of Hall current. It likely occurs for all Hall thrusters. As flow rate is increased to run the thruster at peak thrust and power, this hump presents a potential control issue by providing a second operating point at a low voltage. On the other hand, testing at NASA GRC in 1997 did give some indication that it is possible to return to normal operation by reducing flow rate. ${ }^{2}$

A second feature to note that array voltage can reach $430 \mathrm{~V}$ for a nominally $300 \mathrm{~V}$ array. For EXPRESS, beginning of life array voltage must account for the decrease due to projected radiation damage. For DS-1, voltage rises due to Low Intensity, Low Temperature (LILT) behavior of the solar cells. At a nominal design voltage not much higher than $300 \mathrm{~V}$, the true operational voltage range, coupled with derating requirements may begin to raise some component issues in any payload converter or regulators. This effect must be accounted for in the overall system design.

A third characteristic of interest is the current oscillations at several $\mathrm{kHz}$ frequency exhibited by all Hall thrusters, especially once they have aged. For example, the BPT- 4000 has oscillations at roughly 28 $\mathrm{kHz}$ that can have a peak magnitude comparable to $50 \%$ of the DC current level and sometimes more. These current oscillations are thought to involve interactions between the local flow rate and xenon density in the acceleration channel. They could have three potential impacts: collapse of the array voltage, shifting to operation at the low voltage stable point, and generation of conducted EMI. However, there is strong evidence from the NASA GRC test in 1997 that an appropriately sized capacitance, possibly with additional filtering, can isolate the thruster oscillations sufficiently from the power bus and the arrays.

Finally, a method for controlling the start up must be addressed. Unlike a converter controlled discharge supply, the discharge voltage cannot be as easily turned 
on and off or brought on gradually with a direct drive system. Typically, the impedance of the thruster temporarily drops while the initial ions are created and accelerated out of the acceleration channel. The surge in current can collapse the array, potentially affecting the spacecraft payload bus or operation of another Hall thruster. Several methods have been proposed for controlling start up with anode flow rates. Development of a start method acceptable to the rest of the spacecraft bus is a primary objective of follow on system testing to be discussed later.

\section{Mass Benefit Analysis}

\section{Initial Four Cases}

An analysis was conducted to quantify the projected mass benefit of using a direct drive configuration for the initial four cases involving two spacecraft and two Hall thrusters. Details on the assumptions and scale factors can be found in Reference 5 . Table 2 summarizes the results for each case with mass reduction categories broken out.

The first block details the projected mass savings for the PPU. The discharge supply is eliminated. The EMI filter mass is assumed to be cut in half. We do not believe that the entire filter can be removed without propagating conducted EMI throughout the power bus at a level that will be unacceptable to a spacecraft integrator. In all, 65\% of the BPT PPU mass and 50\% of the SPT-100 PPU masses was projected to be saved. For the SPT-100 the lower fraction saved reflects conservativism because less specific information on the internal design was available.

The second area of mass reduction involves the thermal control that would be dedicated to removing the PPU waste heat. Since firings for the EXPRESS cases ( 1 and 2) are of low duty cycle, phase change heat sinks were assumed for the conventional PPUs at $4.6 \mathrm{~kg} / \mathrm{MJ}$ to absorb the transient heat generated over an NSSK maneuver. ${ }^{23}$ As will be seen for orbit raising, this is a conservative assumption of direct drive mass benefit. The thermal management mass saved from the conventional baseline on the DS- 1 cases ( 3 and 4) was calculated with a value of $44 \mathrm{~kg} / \mathrm{kW}$ assuming a steady state load. ${ }^{24}$

The thermal power eliminated by eliminating the discharge converter also represents electric power not needed from the EPS. For the EXPRESS cases, the resulting power averaged over the duty cycle is insignificant; the NSSK thrusters do not drive spacecraft power. However, for DS-1, we calculated the effective reduction in array size, shunt regulator, and PMAD cabling due to the reduced power required to produce the same thrust. The sum of these three categories represents mass reduction that can only be obtained with a direct drive configuration.
The next section of the table projects the net effect on spacecraft mass of changing the power system components from their baseline bus voltage to $300 \mathrm{~V}$, and in the DS- 1 cases, includes a $0.8 \mathrm{~kg}$ penalty for the payload power step down converter. Based on studies of PMAD mass as a function of voltage, ${ }^{5,7}$ these show additional savings for the $300 \mathrm{~V}$ bus. Since a direct drive configuration is not actually necessary to achieve these savings, they are broken out separately in the table. However, these EPS mass reductions will necessarily be realized as a consequence of implementing direct drive.

Finally, the impact of a $300 \mathrm{~V}$ battery was investigated. The study indicated that, if lithium ion technology were adopted, a high voltage battery was not only feasible but potentially significantly lighter than $\mathrm{NiH} 2$ batteries at the baseline voltage. The results are included in the table for reference. However, a full evaluation of the issues associated with using lithium ion batteries for bus voltages this high was outside the scope of this study. Since this change also could be made independently of using direct drive, and since this was the most uncertain part of the analysis, the battery mass reductions were listed separately from the other mass reductions.

\section{High Power Geosynchronous Orbit Raising}

Cases 1 and 2 assumed North-South Station Keeping (NSSK) as the only function of the Hall thrusters and considered spacecraft only up to $5 \mathrm{~kW}$. However, Hall thrusters have been proposed to perform partial electric orbit raising (EOR), and most modern geosynchronous spacecraft are somewhat more powerful than $5 \mathrm{~kW}$. In addition to the already identified PPU mass reductions with direct drive, the thermal management mass must handle a continuous load instead of a transient load assumed for NSSK. Also, for the $25 \mathrm{~kW}$ case, an extra Hall thruster would be used to accommodate the power. In that case, an extra $8.2 \mathrm{~kg}$ would be saved in the extra PPU by direct drive.

Furthermore, the reduction in PPU inefficiency now allows more EOR per unit time, which has a quantifiable value, especially for commercial missions. Direct drive increases thrust by $\sim 8 \%$ for the same power, allowing more bipropellant mass to be offset, and putting more mass on orbit in the same amount of time. One way to roughly estimate this effect is to assume that the payload delivered to orbit is comparable to that which would be delivered if the EOR were allowed for $8 \%$ more than 90 days. Using that assumption, the analysis in references 8 and 9 indicate an increase in payload to orbit on the order of 15 to $50 \mathrm{~kg}$ for 10 to $25 \mathrm{~kW}$ of spacecraft power. These estimates are for a $\sim 2200 \mathrm{~kg}$ class spacecraft launched from an Atlas IIA. These results are conservative since the analysis ${ }^{8,9}$ was made with thrust to power levels below those the BPT-4000..$^{19}$ 
Finally, significant mass would be saved by increasing the EPS voltage to $300 \mathrm{~V}$, from an assumed baseline of $70 \mathrm{~V}$, as extrapolated from case 2 . Table 3 summarizes the increase in payload to orbit with direct drive for a high power, geosynchronous spacecraft from an Atlas IIA for EOR and NSSK. The results are in terms of the increase in payload delivered to orbit, which is a combination of increased beginning of life (BOL) mass due to increased EOR thrust and non-payload dry mass reductions. Overall, the changes associated with direct drive for an Atlas IIA launch could result in over a $10 \%$ increase in payload relative to the conventional baseline for a $25 \mathrm{~kW}$ spacecraft.

Another analysis of electric orbit raising (ref 10) casts the benefits of EOR in terms of the differential rate of mass to orbit, which incorporates the fact, that for a commercial spacecraft, time to orbit is as valuable as the amount of mass. In the "three stage model" of this analysis, the launch vehicle is assumed to put the spacecraft in an elliptical orbit with sub-synchronous apogee. A biprope!lant apogee motor then raises the perigee to achieve a subsynchronous circular orbit, from which EOR is conducted. This transfer scheme avoids most of the added radiation damage to the arrays by quickly lifting the spacecraft above the radiation belts prior to the extended EOR. Since the circularization action by the onboard bipropellant motor is shown to be insensitive to apogee altitude for the range studied, increasing EOR time effectively unloads delta velocity from the launch vehicle, which has a specific impulse well below that of a Hall thruster. The analysis shows that the mass transfer rate is proportional to the thrust of the engine:

$$
d M / d t=0.5 T / g l_{s p L}-T / g l_{s p E P}
$$

where $T$ is the thrust, $I_{s p L}$ is the launch vehicle effective specific impulse, and $I_{\text {spEP }}$ is the EP system specific impulse.

For a $9 \mathrm{~kW}$ spacecraft, the impact of EOR using SPT$140 \mathrm{~s}$, which has nominally similar performance to the BPT-4000, was given as a differential rate of 8.81 $\mathrm{kg} /$ day from a Sea Launch and $10.75 \mathrm{~kg} /$ day from an Ariane 5. The impact of direct drive over conventional EOR would be to improve the differential mass rate by $8 \%$ or $.70 \mathrm{~kg} /$ day and $.86 \mathrm{~kg} /$ day, respectively.

The maximum mass to orbit for this transfer scheme is limited by the available lower limits for launch vehicle apogee altitude. At $9 \mathrm{~kW}$, EOR from the lowest altitudes analyzed was calculated to take 38 days for the maximum mass off of Sea Launch and 80 days for the Ariane 5 using a conventional Hall thruster system. Direct drive would allow the same maximum mass to orbit to be transferred in about 35 and 74 days respectively, which is an increase of 25.3 and $65 \mathrm{~kg}$ to orbit relative to a conventional Hall thruster in the same time. When added to the the PPU, heat rejection, and high voltage EPS mass savings for $a \sim 10 \mathrm{~kW}$ spacecraft from Table 3, this becomes a $133 \mathrm{~kg}$ increase in net payload to orbit in a 35 day transit for the Sea Launch. The total is a $172 \mathrm{~kg}$ increase in a 74 day transit for the Ariane.

Since the differential rate of mass to orbit is proportional to thrust, the impact of direct drive should be proportionally greater for higher power spacecraft. By extrapolation, a $25 \mathrm{~kW}$ spacecraft would have a conventional rate of $29.9 \mathrm{~kg}$ /day from an Ariane 5 . Direct drive would then increase this by $2.4 \mathrm{~kg} /$ day. Unfortunately, data is not yet available for performing the EOR scheme described in this analysis below an apogee altitude of $20,000 \mathrm{~km}$ for Ariane, which a 25 $\mathrm{kW}$ spacecraft would accomplish in only 29 days. Performing EOR from that altitude is equivalent to performing only 400 out of $1860 \mathrm{~m} / \mathrm{s}$ of possible orbit raising with the more propellant efficient EOR. If even more of the orbit raising were shifted to EOR, a high power, direct drive spacecraft could save more mass well within an acceptable transfer time. For example, the impact of direct drive on a $25 \mathrm{~kW}$ spacecraft performing EOR over a longer, 60-day transit from an Ariane, would increase projected $\mathrm{BOL}$ mass to orbit by $144 \mathrm{~kg}$ over conventional drive. Adding the PPU, thermal management, high voltage EPS mass savings, yields a total of up to $371 \mathrm{~kg}$ more payload on orbit due to direct drive.

It was also shown that the maximization of differential rate of mass to orbit yields the interesting result that the optimum specific impulse for the electric propulsion system should be four times the specific impulse of the launch vehicle upper stage:

$$
i_{\text {spEP }}^{*} \sim 4 \times i_{\text {spl }}^{*}
$$

At an effective specific impulse of 170 to 210 seconds for the two launch vehicles examined, this yields an optimum specific impulse for the EOR in the range of 800 seconds for the three-stage model. For a "twostage" model involving an optimization between only onboard chemical and electric propulsion, the optimum specific impulse is four times the bipropellant apogee motor specific impulse or $\sim 1300 \mathrm{~s}$. This shows that lower operating voltages, which produce lower specific impulses, should be advantageous for orbit raising, as long as thrust efficiency is maintained. A low optimum voltages has significant implications for SEP direct drive since lower voltages are easier to implement.

However, the low optimum operating voltage for orbit raising has one system level complication: NSSK should be performed at higher specific impulse, on the order of $2000 \mathrm{~s}$, to conserve propellant mass. The BPT4000 requires $400 \mathrm{~V}$ to achieve such specific impulse. This hints that a direct drive application involving both orbit raising and NSSK might require some form of multi-mode system. For example, the arrays and electric power system bus could be designed for $200 \mathrm{~V}$ operation with a reconfigurable option to run the Hall 
thrusters at $400 \mathrm{~V}$ for NSSK. The analysis of the net mass benefit of such a system is more complex, requiring further work.

To value the improvements discussed above, one could take as a baseline the incremental launch cost defined as the launch vehicle cost divided by the BOL mass on orbit with no EOR. ${ }^{10}$ This is the cost to put more mass on orbit by purely conventional chemical propulsion, ignoring the limited scalability of launch mass per launch vehicle. For Sea Launch and Ariane, these numbers are given as 26.1 and $29.5 \mathrm{kS} / \mathrm{kg}$. ${ }^{10}$ The net revenue value of assets on orbit should exceed at least their launch cost. In order to account for the cost of additional days in transit during EOR, operational costs and interest costs at an assumed interest rate of $10 \%$ were estimated at $\$ 120 \mathrm{k} / \mathrm{day}$. This number divided by the differential mass rate to orbit must be less than the incremental launch cost for EOR to have a beneficial cost impact. A key advantage to direct drive mass savings is that it does not involve any lengthening of transit time. It can be considered purely as additional mass on orbit without added EOR operational and interest costs. By this simple assessment, the $133 \mathrm{~kg}$ extra on orbit due to direct drive for a 35 day EOR transit from a Sea Launch is worth $\$ 3.5 \mathrm{M}$. The $172 \mathrm{~kg}$ extra in a 74 day transit on the Ariane is worth $\$ 5.1 \mathrm{M}$.

\section{Extended Deep Space Mass Benefit}

The baseline cases 3 and 4 examined the impact of direct drive specifically on the DS- 1 mission and an analog with twice its power. Since this only showed a relative comparison between direct drive and a conventional Hall thruster system, this begs the question of how direct drive projections compare with the actual NSTAR ion engine system. This analysis examines whether a Hall thruster, even with direct drive, can be mass competitive for a deep space mission, where high specific impulse is favored. Preliminary analysis is also presented on how this trade extends to higher power spacecraft on large delta velocity missions now under consideration.

The most applicable comparison for the DS-1 mission is with the SPT-100 since it has thrust levels that match that of the NSTAR ion engine within the 2.5 $\mathrm{kW}$ power capability of DS-1. In fact, for comparison purposes, we assumed that the SPT-100 would be run with the same thrust as the NSTAR engine to match the actual mission profile of DS-1. The BOL spacecraft mass was constant at $486 \mathrm{~kg} .^{12}$ Any mass differences in the propulsion system or propellant required were assumed to result in a delta to the available payload mass relative to that actually flown on DS-1. Thruster mass, PPU mass, thermal management of PPU waste heat, and electric power system mass were compared for system dry mass. Relative propellant required was calculated simply as a function of delta velocity. No relative difference in propellant margin, tankage fraction, or structural mass was included in this assessment.

The results in terms of mass available for payload relative to DS-1 are plotted as a function of delta velocity on Figure 4 . Note that the actual mass of the DS-1 arrays, ${ }^{22}$ built prior to 1998 , is somewhat heavier than the array specific powers used throughout the study for extrapolation of future electric power systems. This accounts for a $16 \mathrm{~kg}$ improvement, as noted with the dashed line. The dry mass of a conventional SPT100 system is almost another $20 \mathrm{~kg}$ lighter than the NSTAR hardware, even with advanced arrays. The SPT-100 thruster and PPU are both lighter. Thermal management mass is slightly heavier due to the higher losses in the SPT-100 PPU. The electric power system mass, including the solar arrays, shunt regulator and cabling, was sized for about $500 \mathrm{~W}$ less power for the SPT-100 in order to give the same thrust with the SPT100 relative the to NSTAR engine. This allowance results in roughly $12 \mathrm{~kg}$ of dry mass savings for the SPT-100 case.

To calculate propellant requirements, a mission average specific impulse was determined based on the power availability profile during the actual DS-1 mission. The mission average insolation and power was roughly $65 \%$ of the maximum at $1 \mathrm{AU}^{22}$ For the SPT-100, this was estimated to give a specific impulse of $1425 \mathrm{~s}$. For the ion engine, actual data on delta velocity and propellant usage were used to give an average specific impulse of $2850 \mathrm{~s}$, or twice that of the Hall thruster. ${ }^{13}$ Consequently, the dry mass advantage of the Hall thruster system disappears at higher delta velocities. However, it should be noted that even the conventional Hall thruster system is competitive with the actual NSTAR masses out to the baseline mission delta velocity of $1320 \mathrm{~m} / \mathrm{s}$. Since the qualified life of the SPT- 100 corresponds to a delta velocity on the order of $5000 \mathrm{~m} / \mathrm{s}$ for a spacecraft the size of DS-1, thruster life is not a limiting factor for this mission. The impact of direct drive and high voltage EPS mass savings is to shift this region of competitiveness to higher delta velocities by over $1500 \mathrm{~m} / \mathrm{s}$, which puts its breakeven point well beyond even the NEAR mission delta velocity, which used a chemical engine. At the DS-1 extended mission limit, the direct drive Hall thruster falls behind the NSTAR system by $\sim 10 \mathrm{~kg}$. However, this comparison shows that a direct drive system with a high voltage bus can be competitive in mass with the NSTAR baseline out to several $\mathrm{km} / \mathrm{s}$ where Mars and Venus rendezvous missions become possible.

A higher power comparison was made to the Dawn spacecraft, which sports a $7.5 \mathrm{~kW}$ array and a somewhat heavier payload. The baseline for this mission, due to be launched in 2006, uses three NSTAR engines firing at $90 \mathrm{mN}$ each (at $1 \mathrm{AU}$ ). This level of thrust falls within the range of a BPT- 4000 , which requires less input power but has lower specific impulse. 
Performing a similar assessment as the SPT-100 on DS-1, the results are shown on Figure 5. Since the thrust of three NSTAR ion systems can be provided by a single BPT-4000 at almost $3 \mathrm{~kW}$ less input power, the dry mass is $100 \mathrm{~kg}$ lower for even a conventional Hall thruster system. The mission average specific impulse for the BPT-4000 is estimated at 1740 seconds based on an assumption that the mission average power is $65 \%$ of the power required to provide $270 \mathrm{mN}$ at 1 AU. The NSTAR engines are assumed to run at $3000 \mathrm{~s}$ average throughout the mission. The impact of the lower specific impulse for the BPT-4000 overwhelms the dry mass advantage at about $5 \mathrm{~km} / \mathrm{s}$.

The impact of direct drive and a high voltage bus is to extend the region of competitiveness by $3 \mathrm{~km} / \mathrm{s}$. The projected direct drive payload is only $20 \mathrm{~kg}$ behind at $10 \mathrm{~km} / \mathrm{s}$, which is the velocity increment for the Dawn mission and the low end for the Deep Space Design Reference Mission to Saturn or beyond. However, the currently planned qualification lifetime for the BPT4000 limits its operation for a snacecraft the size of Dawn to about $6 \mathrm{~km} / \mathrm{s}$. Either design modifications would be needed to extend the life of the BPT-4000 significantly, or a second thruster with some form of switching in the PPU would be needed. The mass penalty for the extra thruster string has not been assessed in detail, but could be on the order of $20 \mathrm{~kg}$.

Overall, the impact of direct drive on deep space missions is to extend the delta velocity for which a Hall thruster could be considered. A general expression for the payload mass can be written as:

$M_{P}=M_{0} e^{-\Delta v / g l s p}-\alpha P-M_{\text {fixed }}$,

where $M_{0}$ is the launch mass, $P$ is the spacecraft power, and $\mathbf{M}_{\text {fixed }}$ is any non-payload mass not proportional to power. $\alpha$, the specific power mass, has several components:

$\alpha=\alpha_{\text {Thrus }}+\alpha_{\text {PPU }}+\alpha_{\text {Heat }}\left(1-\eta_{\text {PPU }}\right)+\alpha_{\text {Pwr }}$,

where the terms refer to the specific power mass of the thruster, PPU, PPU heat rejection and power system (including arrays, regulator and cabling), respectively. The relative payload mass for a direct drive system relative to a baseline system, denoted by the superscript, o, would be:

$$
\Delta M_{P}=M_{o}\left(e^{-\Delta v / g l s p}-e^{-\Delta v / g l s p^{\circ}}\right)-\left(\alpha P-\alpha^{\circ} P^{\circ}\right)
$$

$P$, the power required to get the same thrust with direct drive as for the baseline system, can be related to the baseline power, $\mathrm{P}^{\circ}$ by:

$P=\frac{g T I_{s p}}{2 \eta}=\frac{g}{2 \eta} \cdot\left(\frac{2 \eta^{\circ} P}{g l_{s p}^{\circ}}\right) \cdot I_{s p}=\frac{\eta^{\circ}}{\eta} \frac{I_{s p} p}{I_{s p}^{\circ} p}$

where $\eta$ is the total thrust efficiency, including PPU efficiency, and $T$, the thrust is held equal for both systems. Using this relationship and the approximation that $\mathrm{e}^{\mathrm{x}} \approx 1+\mathrm{x}$ for $\mathrm{x}<<1$, the relative payload mass can be simplified to:

$$
\Delta M_{p}-P\left(\alpha^{0}-\alpha \frac{\eta^{0}}{\eta} \frac{I_{s p}}{I_{s p}^{o}}\right)-\frac{M_{0} \Delta v}{g}\left(\frac{I_{s p}^{o}-I_{s p}}{I_{s p}^{0} \cdot I_{s p}}\right)
$$

Direct drive principally reduces $\alpha$, making the first term more positive. It also has a secondary effect of increasing the system efficiency, $\eta$, by increasing the PPU efficiency, further increasing the positive first term. Also apparent from this equation is the fact that the benefits of direct drive for deep space missions will tend to increase for missions with a high power level. Working against the mass benefits of direct drive is the fact that the implementation of SEP direct drive tends to favor a lower specific impulse, $I_{s p}$, than the baseline ion engines due to the relative ease of operating in direct drive at a lower voltage. The negative impact of a lower specific impulse is exacerbated for missions with large launch mass and large delta velocities, such as the Deep Space Design Reference Mission.

In summary, the deep space missions to which SEP

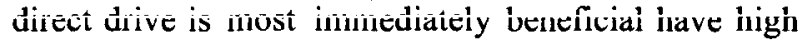
power and low delta velocity. Working to raise the operating voltage for which direct drive is feasible will also open more of the mission space for which it is potentially beneficial.

\section{Hardware Development Status}

Aside from high voltage arrays, the most critical hardware in a direct drive system is the propulsion power electronics. In order to investigate system level considerations and ultimately to demonstrate solar array compatibility with a Hall thruster running at full power in direct drive mode, Aerojet is developing a breadboard level direct drive propulsion power unit (PPU) in conjunction with the rest of the direct drive program efforts. The key objectives for use of this hardware are:

- Demonstration of a PPU designed specifically to operate in direct drive mode

- Demonstration of a $5 \mathrm{~kW}$ class Hall thruster operating at full power in direct drive mode.

- Test of a segment of $300 \mathrm{~V}$ solar array in the plume of a Hall thruster while electrically coupled

- Demonstration of an acceptably soft Hall thruster startup in direct drive mode

- Characterization of the dynamic behavior of the coupled Hall thruster/solar array circuit, especially near the short circuit current.

Although the majority of the mass and almost all of the thermal dissipation can be eliminated from the PPU in a direct drive system, the electronics that remain are critical to the operation and control of the system. Figure 6 illustrates the major pieces of a conventional PPU and the parts that would be eliminated or retained for direct drive. Each block is proportionally representative of the PPU board area of a conventional Hall thruster PPU. While the Heater Keeper Magnet (HKM) supply, Auxiliary (AUX) supply, xenon flow 
control drivers, and most of the control electronics would stay largely the same, the main power converters and their control circuits are completely eliminated from the design. The input and output filters will not be identical for the direct drive, but will have some similarities, especially for input filtering for the HKM and AUX and the output filter to the thruster. Overall, the board area savings are approximately $50 \%$. Mass savings is expected to be closer to $65 \%$ due to the fact that the power converters are significantly heavier than control circuits.

The design of the breadboard PPU system (Figure 7) is based on sections of the conventional Hall thruster PPU currently under development at Aerojet. ${ }^{25}$ The heart of the direct drive PPU, the HKM and AUX circuits, are nearly identical to those in the Engineering Qualification Model PPU, which is to be flight qualified at Aerojet starting this year. These circuits are outlined in red in Figure 8.

Other "hoise keening" functions necessary for a flight direct drive PPU have been incorporated with less flight-like designs in the breadboard PPU. The output telemetry (TLMY) in the conventional PPU was originally measured in the discharge supply modules (DSM). Due to the higher input voltages, a new sensing architecture will be implemented and tested. A personal computer replaces the computational portion of the "house keeping" circuits. The graphic user interface will be used to command all functions of the direct drive PPU, as well as record and log telemetry data. A customized set of discrete logic circuits allows the Labview driven computer boards to operate the HKM circuit several distinct modes for flexibility during development. These modes include heater only, keeper only, magnet only, keeper and magnet in series, and start sequences. For a flight unit the computer and discrete logic would be replaced with a field programmable gate array or equivalent. Finally, commercially available mass flow controllers replace the xenon flow control and valve driver circuits from the conventional PPU. A direct drive PPU is likely to need separate cathode and anode flow control to allow for added control during start up. A simple analog interface with Celerity (Unit) xenon mass flow controllers allows maximum flexibility in development at minimum cost.

As discussed earlier, the startup of a Hall thruster presents a key challenge for direct drive implementation. Principally, the issue is that the thruster goes through a region of low impedance on its way to steady state operation. In a converter based topology the voltage can either be ramped up or allowed to drop while the current is limited until steady state impedance is established. In a direct drive mode, however, the voltage cannot be controlled independently and the current reaches a limit only when the solar array collapses, which is not desirable, either for thrusters connected in parallel or for the spacecraft bus. Independent control of the anode flow rate returns one degree of freedom to the system. Start sequences that involve ramping anode flow rate with the addition of magnet current will be substituted for the control provided by a power converter. The discrete logic board allows rapid start command sequences in cases where the computer interface is not fast enough.

The extent of filtering required in a direct drive PPU is to be determined in future development tests. This represents the largest uncertainty in mass reduction from a conventional PPU. The elimination of the main switch mode power supplies suggests that some filtering can also be eliminated. However, the full extent to which filtering can be avoided in favor of a straight bus connection between the solar array and the thruster discharge depends on the dynamic interaction between the electrical characteristics of the discharge and the solar array. At a minimum, the 1997 tests at $G^{2} C^{2}$ showed the need for "output" capacitance to the thrister on the order of $15 \mathrm{HF}$. In addition, an isolation relay will likely be a requirement of any flight system. SPICE model analysis is planned, integrating the characteristics of the BPT-4000 discharge with those of a typical solar array and cable assembly. The breadboard PPU is being designed with space to allow the addition of filtering components during development.

The direct drive PPU must be powered by a solar array simulator and a $70 \mathrm{~V}$ lab supply to be supplied in follow on testing. The array simulator must provide a nominal $-300 \mathrm{~V}$ with characteristics that mimic the voltage-current characteristics of a typical array, such as shown in Figure 2. The $70 \mathrm{~V}$ supply represents a low voltage bus for low power functions such as house keeping and magnets. In an actual flight design, the HKM and AUX circuits could be modified to operated directly off of the $300 \mathrm{~V}$ bus.

The direct drive PPU will be completed and assembled into a rack mount chassis by the end of July. Subsequent functional testing and bench top testing is planned for another two months. The PPU will be available for demonstration testing in early GFY04.

\section{Conclusions}

Overall, direct drive promises solid mass reductions for both geosynchronous and deep space missions. Because of the premium on time, geosynchronous missions with electric orbit raising derive the most benefit from direct drive. For the four initial cases examined, savings due to the propulsion system and associated high voltage bus ranged from 19 to $63 \mathrm{~kg}$. Despite the fact that propulsion represents only a small fraction of the mission average power on the geosynchronous missions, there are 4 PPUs on board, which represent the largest propulsion related savings. 
When the analysis for geosynchronous spacecraft is extended to electric orbit raising for spacecraft power up to $25 \mathrm{~kW}$, the savings due to propulsion and the high voltage bus was up to $278 \mathrm{~kg}$ or $>10 \%$ of the $\mathrm{BOL}$ mass from an Atlas IIA launch. Another analysis of a $\sim 10 \mathrm{~kW}$ bus showed $133 \mathrm{~kg}$ of savings from a Sea Launch and $174 \mathrm{~kg}$ savings from an Ariane 5 launch. This analysis, which maximized the rate of mass transfer to geosynchronous orbit, shows a linear dependence of rate on thrust. Higher powers will increase the rate proportionally, although for EOR from $20,000 \mathrm{~km}$ and above, the increased power simply reduces the transit time. The increases in payload for geosynchronous spacecraft are valued at up to $\$ 5 \mathrm{M}$ in launch costs.

For the DS-1 cases, the reduction in heat rejection mass is the largest of the components associated directly with the propulsion. The savings for the $300 \mathrm{~V}$ EPS components are not particularly large because the baseline bus voltage was already $90 \mathrm{~V}$. A comparison between the NSTAR system and a direct drive system for DS-1 or Dawn show that the direct drive Hall thruster system can be mass competitive, especially for higher power spacecraft and lower delta velocity missions. At high delta velocities, the lower specific impulses for near term solar direct drive concepts overwhelm the system dry mass savings with increased propellant mass. However, the impact of direct drive is to extend the mission space for which a Hall thruster could be considered as an alternative to an ion engine to include several interesting missions.

Fabrication of a direct drive propulsion power unit is well underway and will be ready for testing late in 2003. This hardware is the key complement to the high voltage solar array also being developed by the Direct Drive Hall Thruster team.

\section{References}

1. Jongeward, G. A., et al. "High Voltage Solar Arrays for a Direct Drive Hall Effect Propulsion System." IEPC Paper 01-327, 27 $7^{\text {th }}$ International Electric Propulsion Conference, Pasadena, CA, 2001.

2. Hamley, J. A., et al. "Hall Thruster Direct Drive Demonstration." AIAA Paper 97-2787, $33^{\text {rd }}$ Joint Propulsion Conference, Seattle, WA, 1997.

3. Mikellides, I. G., et al. "Assessment of High-Voltage Solar Array Concepts for a Direct Drive Hall Effect Thruster System." AIAA Paper 2003-4725, $39^{\text {th }}$ Joint Propulsion Conference, Huntsville, AL, 2003.

4. Schneider, T. et al. "Experimental Investigation of Plasma Interactions with Candidate Solar Array Technologies for a Direct Drive Hall Thruster System." AIAA Paper 2003-5017, $39^{\text {th }}$ Joint Propulsion Conference, Huntsville, AL, 2003.

5. Hoskins, W. A. et al. "Direct Drive Hall Thruster System Study." JHU-CPIA: $51^{\text {st }}$ JANNAF Propulsion Meeting, Orlando, FL, Nov., 2002.
6. Kerslake, Thomas W., "Effect of Voltage Level on Power System Design for Solar Electric Propulsion Missions," International Solar Energy Conference, paper ISEC2003-44008, Kohala Coast, Hawaii Island, HI, March 15-18, 2003. (see also NASA TM-2003212304).

7. Reinhardt, K. C and Mayberry, C. S. "Space Power Technology in Power Management and Distribution Electronics." J. Spacecraft and Rockets, Vol. 35, No. 6, 1998, pp. $837-44$.

8. Oleson, S. R. et al. "Advanced Propulsion for Geostationary Orbit Insertion and North-South Station Keeping." AIAA Paper 95-2513, $31^{\text {st }}$ Joint Propulsion Conference, 1995.

9. Oleson, S. R. and Myers, R. M. "Launch Vehicle and Power Level Impacts on Electric GEO Insertion," AIAA Paper 96-2978, 32 ${ }^{\text {nd }}$ Joint Propulsion Conference, 1996.

10. Randolph, T. M. and Oh, D. H. "Economic Benefit Analysis of Chemical-electric Orbit Raising Missions." AIAA Paper 2002-1980, $38^{\text {th }}$ Joint Propulsion Conference, 2002.

11. Sovie, J. "The NASA Space Power Technology Program." NASA GKC Presentation, space Power Workshop, Redondo Beach, CA, 23 April, 2002.

12. Deep Space 1: Quick Facts, http://nmp.jpl.nasa.gov/ dsl/quick_facts.html, April, 26, 2002.

13. Rayman, M. D. and Varghese, P. "The Deep Space 1 Extended Mission." Acta Astronautica, Vol 48, p. 693-705, 2001.

14. Jenkins, J. E. and Dakermanji, G. "Near Earth Asteroid Rendezvous Spacecraft Power System Flight Performance." SAE Paper 1999-01-2485, 1999.

15 Dawn Mission homepage. http://wwwssc.igpd.ucla.edu/dawn/spacecraft.html, June 26, 2003.

16. Dudzinski, L. A. and Myers, R. M. "Advanced Propulsion Benefits to New Millennium Class Missions." $9^{\text {th }}$ Conference on Small Satellites, Logan, UT, 1995.

17. Bober, A. et al. "Development and Qualification Test of a SPT Electric Propulsion System for "GALS" Spacecraft." IEPC Paper 93-008, 23 $3^{\text {rd }}$ International Electric Propulsion Conference, Seattle, WA, 1993.

18. Brophy, John R., "Stationary Plasma Thruster Evaluation in Russia," Summary Report, NASA Jet Propulsion Laboratory, JPL Publication 92-4, March $15,1992$.

19. DeGrys, K., et al. "Development and Testing of a 4500 Watt Flight Type Hall Thruster and Cathode." IEPC Paper 01-011, 27th International Electric Propulsion Conference, Pasadena, CA, 2001.

20. Manzella, D. H., Jacobson, D. T. and Jankovsky, R. S. "High Voltage SPT Performance." AIAA Paper 2001 $3774,37^{\text {th }}$ Joint Propulsion Conference, Salt Lake City, 2001.

21. Fact Sheet at http://www.spectrolab.com, April 10, 2002.

22. Murphy, D. M. "The Scarlet Solar Array: Technology Validation and Flight Results." in Deep Space 1 Technology Validation Report. http://nmp-techvalreports.jpl.nasa.gov/DS 1/Scarlet_Integrated_Report.p df, downloaded April 26, 2002. 
23. Ashford, V. A. et al., "Battery Thermal Control Using Paraffin Heat Sinks." Energy Sciences Laboratory Presentation, Space Power Workshop, Redondo Beach, CA, 23 April, 2002.

24. Kerslake, T., "Electric Propulsion Reboost of International Space Station." NASA Internal Study, Oct, 2001.
25. Fisher, J. F. et al. "The Development and Qualification of a $4.5 \mathrm{~kW}$ Hall Thruster Propulsion System." AIAA paper 2003-4551, , 39 ${ }^{\text {th }}$ Joint Propulsion Conference, Huntsville, AL, 2003.

Table 1. Initial Case Characteristics

\begin{tabular}{|l|c|c|c|c|}
\hline & Case 1 & Case 2 & Case 3 & Case 4 \\
\hline Spacecraft Configuration & Express A & Express A & DS-1 & DS-1 \\
\hline Thruster & SPT-100 & BPT-4000 & SPT-100 & BPT-4000 \\
\hline $\begin{array}{l}\text { Primary Thruster } \\
\text { Function }\end{array}$ & NSSK & NSSK & $\begin{array}{c}\text { Primary Delta } \\
\text { Velocity }\end{array}$ & $\begin{array}{c}\text { Primary Delta } \\
\text { Velocity }\end{array}$ \\
\hline Spacecraft Mass & $2600 \mathrm{~kg}$ & $2600 \mathrm{~kg}$ & $500 \mathrm{~kg}$ & $500 \mathrm{~kg}$ \\
\hline Spacecraft Array Power & $2500 \mathrm{~W}$ & $5000 \mathrm{~W}$ & $2500 \mathrm{~W}(1 \mathrm{AU})$ & $5000 \mathrm{~W}(1 \mathrm{AU})$ \\
\hline Payload Power & $2500 \mathrm{~W}$ & $5000 \mathrm{~W}$ & $500 \mathrm{~W}$ & $500 \mathrm{~W}$ \\
\hline Thruster Power & $1350 \mathrm{~W}$ & $4000 \mathrm{~W}$ & $1350 \mathrm{~W} \pm$ & $4000 \mathrm{~W} \pm$ \\
\hline Payload Bus Voltage & $35 \mathrm{~V} \mathrm{Unreg}$ & $70 \mathrm{~V} \mathrm{Reg}$ & $90 \mathrm{~V} \mathrm{Reg}$ & $90 \mathrm{~V} \mathrm{Reg}$ \\
\hline Thruster Duty Cycle & $6.4 \%$ avg. & $2.3 \%$ avg. & $55 \%$ avg. & $55 \%$ avg. \\
\hline PPUs/ Spacecraft & 4 & 4 & 1 & 1 \\
\hline
\end{tabular}

Table 2. Mass Savings For a Direct Drive system at $300 \mathrm{~V}$

\begin{tabular}{|c|c|c|c|c|}
\hline \multicolumn{5}{|l|}{ Power Processing } \\
\hline Discharge Supply & 9.6 & 19.2 & 2.4 & 4.8 \\
\hline EMI Filter & 1.4 & 2.8 & 0.35 & 0.7 \\
\hline Control + HKM & 0.9 & 0.9 & 0.23 & 0.23 \\
\hline Housing & 5.0 & 10.0 & 1.24 & 2.5 \\
\hline Total PPU Mass Redux / Shipset & $16.9 \mathrm{~kg}$ & $32.9 \mathrm{~kg}$ & $4.2 \mathrm{~kg}$ & $8.2 \mathrm{~kg}$ \\
\hline Fraction of original & $50 \%$ & $65 \%$ & $50 \%$ & $65 \%$ \\
\hline $\begin{array}{l}\text { PPU Heat Rejection } \\
\text { Reduction in Heat Load } \\
\text { Mass of Heat Rejection Hdwr }\end{array}$ & $\begin{array}{l}480 \mathrm{~kJ} \\
8.8 \mathrm{~kg} \\
\text { (per shipset) }\end{array}$ & $\begin{array}{l}500 \mathrm{~kJ} \\
9.2 \mathrm{~kg} \\
\text { (per shipset) }\end{array}$ & $\begin{array}{l}180 \mathrm{~W} \\
7.9 \mathrm{~kg}\end{array}$ & $\begin{array}{l}350 \mathrm{~W} \\
15.4 \mathrm{~kg}\end{array}$ \\
\hline Reduction in EPS Mass due to & - & - & $2.7 \mathrm{~kg}$ & $5.7 \mathrm{~kg}$ \\
\hline Sub-total due to Propulsion & $25.7 \mathrm{~kg}$ & $42.1 \mathrm{~kg}$ & $14.8 \mathrm{~kg}$ & $29.3 \mathrm{~kg}$ \\
\hline Savings for $300 \mathrm{~V}$ EPS & & & & \\
\hline Array Assembly & 15.8 & 9.0 & 2.8 & 5.5 \\
\hline Shunt Regulator & 9.7 & 5.0 & 1.5 & 3.0 \\
\hline PMAD Cabling & 6.3 & 3.7 & 1.1 & 1.2 \\
\hline Power System Enclosure & 4.5 & 3.0 & -0.8 & -0.8 \\
\hline Sub-total due to 300 V EPS & $36.3 \mathrm{~kg}$ & $20.7 \mathrm{~kg}$ & $4.6 \mathrm{~kg}$ & $8.9 \mathrm{~kg}$ \\
\hline $\begin{array}{l}\text { Total Mass Reduction } \\
\text { (Direct Drive + } 300 \text { V EPS) }\end{array}$ & $62.0 \mathrm{~kg}$ & $62.8 \mathrm{~kg}$ & $19.4 \mathrm{~kg}$ & $38.2 \mathrm{~kg}$ \\
\hline Change Battery to $300 \mathrm{~V} \mathrm{Li-lon}$ & $55.6 \mathrm{~kg}$ & $62.5 \mathrm{~kg}$ & $18.2 \mathrm{~kg}^{*}$ & $18.2 \mathrm{~kg}^{*}$ \\
\hline Mass Reduction Incl. Battery & $118 \mathrm{~kg}$ & $125 \mathrm{~kg}$ & $37.6 \mathrm{~kg}^{\star}$ & $56.4 \mathrm{~kg}^{\star}$ \\
\hline
\end{tabular}


Table 3. Mass Savings For High Power, Geosynchronous Spacecraft Associated with Direct Drive

\begin{tabular}{|c|c|c|c|c|}
\hline Spacecraft Power & $10 \mathrm{~kW}$ & $15 \mathrm{~kW}$ & $\underline{20} \mathbf{k W}$ & $25 \mathrm{~kW}$ \\
\hline $\begin{array}{l}\text { BPT-4000 PPUs per Spacecraft } \\
\text { PPU Mass Savings per s/c }\end{array}$ & $\begin{array}{c}4 \\
32.9 \mathrm{~kg} \\
\end{array}$ & $\begin{array}{c}4 \\
32.9 \mathrm{~kg} \\
\end{array}$ & $\begin{array}{c}4 \\
32.9 \mathrm{~kg} \\
\end{array}$ & $\begin{array}{c}5 \\
41.2 \mathrm{~kg} \\
\end{array}$ \\
\hline $\begin{array}{l}\text { Heat Load reduction }\left(\Delta \eta \times P_{i n}\right) \\
\text { Reduction in Thermal Mngmnt }\end{array}$ & $\begin{array}{l}0.75 \mathrm{~kW} \\
33.0 \mathrm{~kg} \\
\end{array}$ & $\begin{array}{l}1.13 \mathrm{~kW} \\
49.5 \mathrm{~kg} \\
\end{array}$ & $\begin{array}{r}1.5 \mathrm{~kW} \\
66.0 \mathrm{~kg} \\
\end{array}$ & $\begin{array}{l}1.88 \mathrm{~kW} \\
82.5 \mathrm{~kg} \\
\end{array}$ \\
\hline $\begin{array}{l}\text { Increase in Payload due to } \Delta \eta \\
\text { Atlas IIA (refs } 8 \text { and } 9 \text { ) }\end{array}$ & $15 \mathrm{~kg}$ & $30 \mathrm{~kg}$ & $50 \mathrm{~kg}$ & $50 \mathrm{~kg}$ \\
\hline $\begin{array}{l}\text { Total for Atlas IIA (due to } \\
\text { propulsn) } \\
\text { Baseline Mass to GEO in } 90 \text { days }^{9} \\
\text { Incr P/L \% Mass to GEO (prop } \\
\text { only) }\end{array}$ & $\begin{array}{l}81 \mathbf{~ k g} \\
\begin{array}{l}2070 \mathrm{~kg} \\
3.9 \%\end{array}\end{array}$ & $\begin{array}{l}112 \mathrm{~kg} \\
2140 \mathrm{~kg} \\
5.3 \%\end{array}$ & $\begin{array}{l}149 \mathrm{~kg} \\
2430 \mathrm{~kg} \\
6.1 \%\end{array}$ & $\begin{array}{l}174 \mathrm{~kg} \\
2580 \mathrm{~kg} \\
6.7 \%\end{array}$ \\
\hline Payload incr. Due to 300 V EPS & $41.4 \mathrm{~kg}$ & $62.1 \mathrm{~kg}$ & $82.8 \mathrm{~kg}$ & $103.5 \mathrm{~kg}$ \\
\hline $\begin{array}{l}\text { Total propuls+EPS mass redux } \\
\text { Incr. P/L \% mass to GEO } \\
\text { (prop+EPS; Atlas IIA) }\end{array}$ & $\begin{array}{c}122 \mathbf{k g} \\
5.9 \%\end{array}$ & $\begin{array}{c}174 \mathbf{~ k g} \\
8.1 \%\end{array}$ & $\begin{array}{c}232 \mathbf{~ k g} \\
9.5 \%\end{array}$ & $\begin{array}{r}278 \mathbf{~ k g} \\
10.8 \%\end{array}$ \\
\hline
\end{tabular}




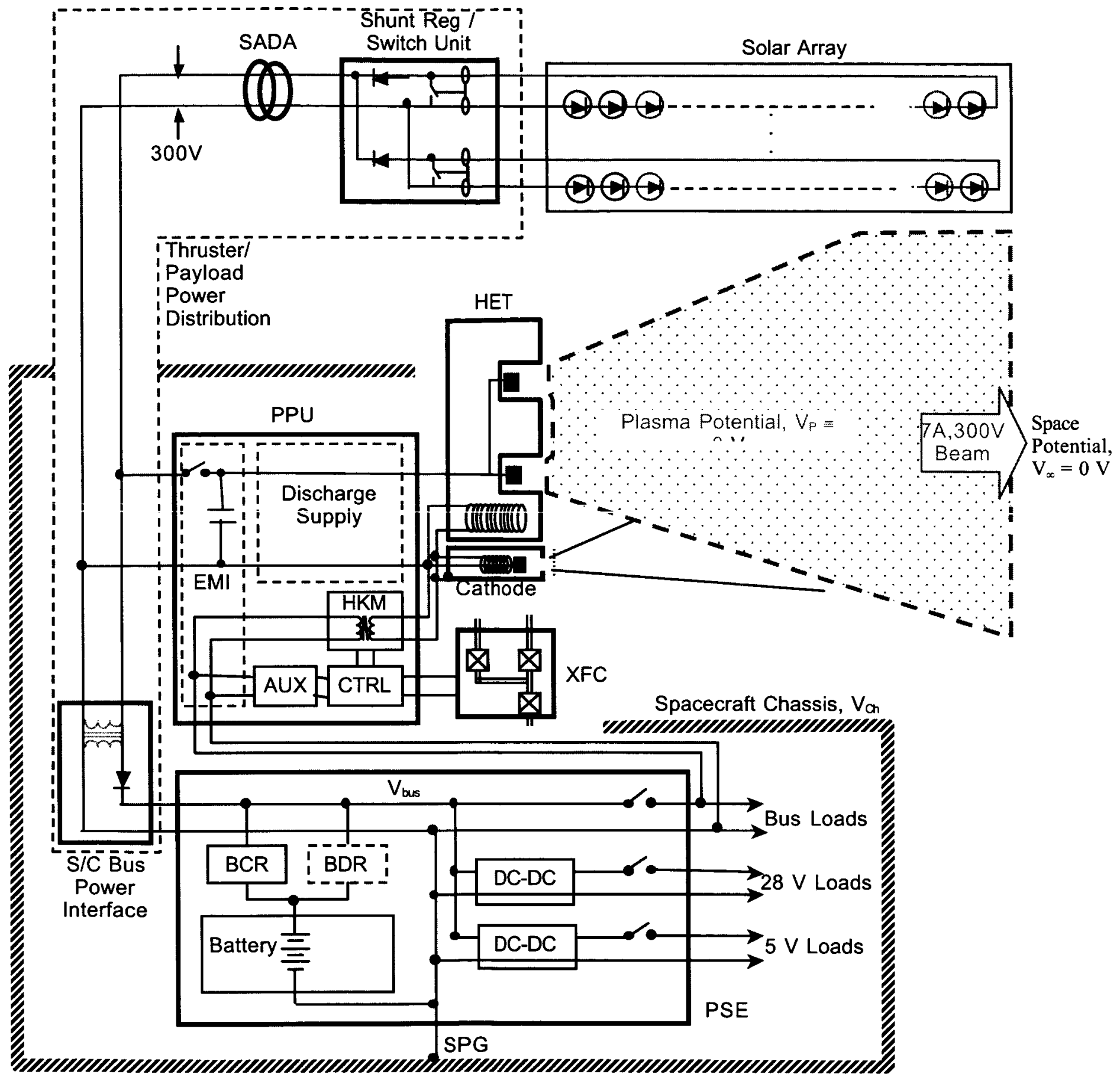

Figure 1. Direct Drive Hall Thruster System

AUX = AUXiliary power supply

BDR = Battery Discharge Regulator

EMI = ElectroMagnetic Interference filter

HKM = Heater/Keeper/Magnet supply

PPU = Power Processing Unit

SPG $=$ Single Point Ground
$B C R=$ Battery Charge Regulator

CTRL = ConTRoL electronics

HT = Hall Thruster

PSE = Power System Enclosure

SADA = Solar Array Drive Assembly

$\mathrm{XFC}=$ Xenon Feed Control 

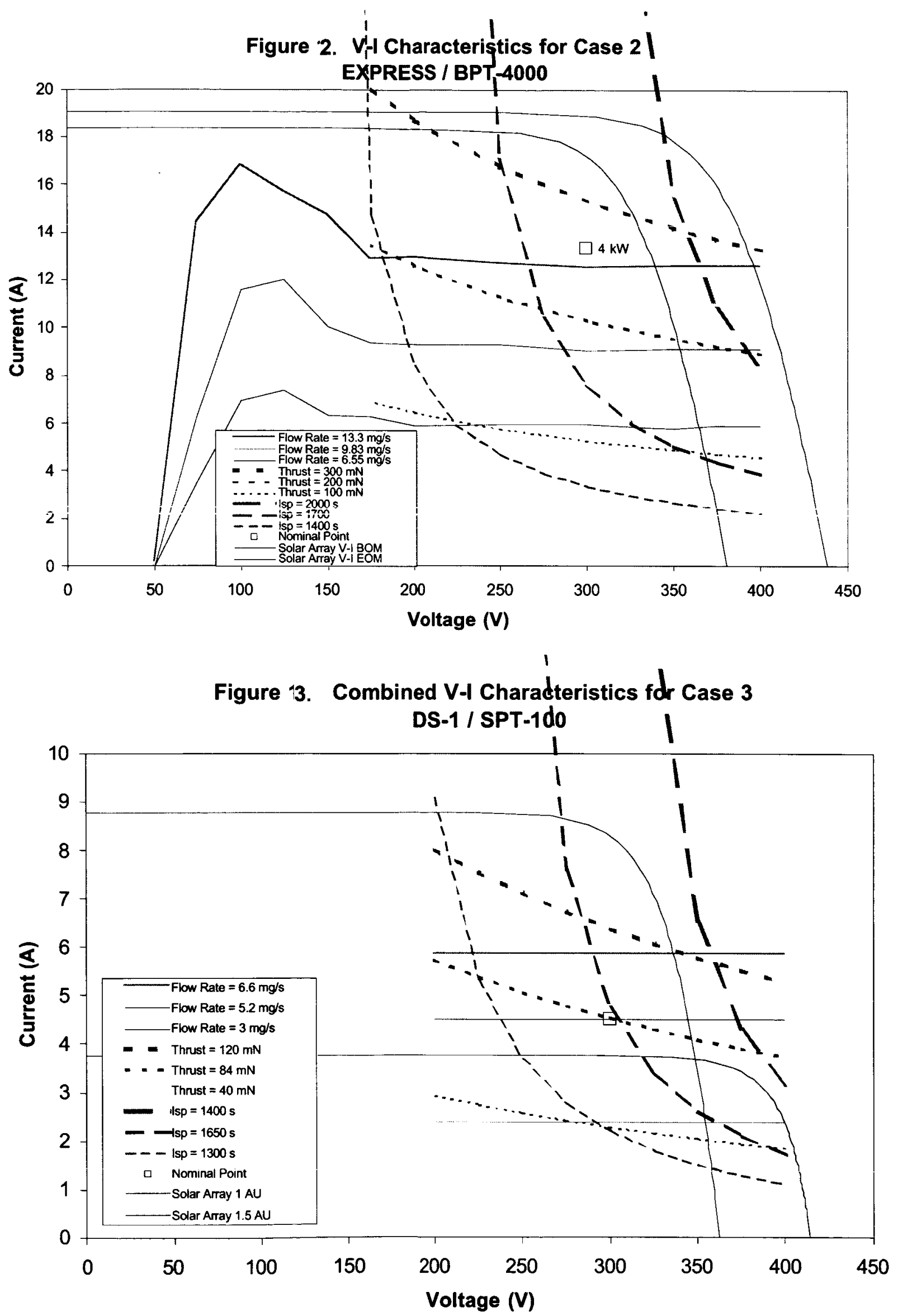


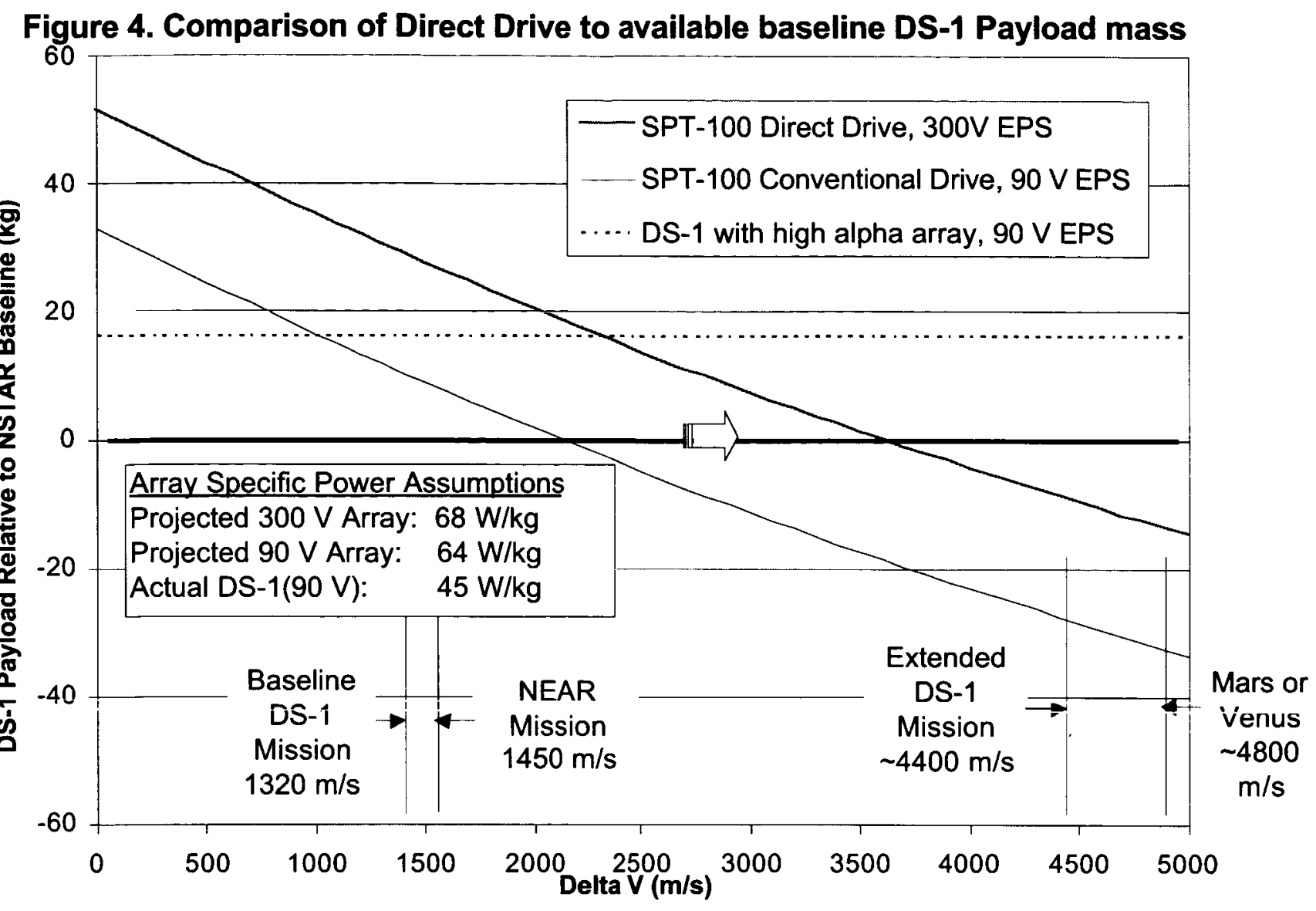

Figure 5. Comparison of Direct Drive to available baseline Dawn Payload mass

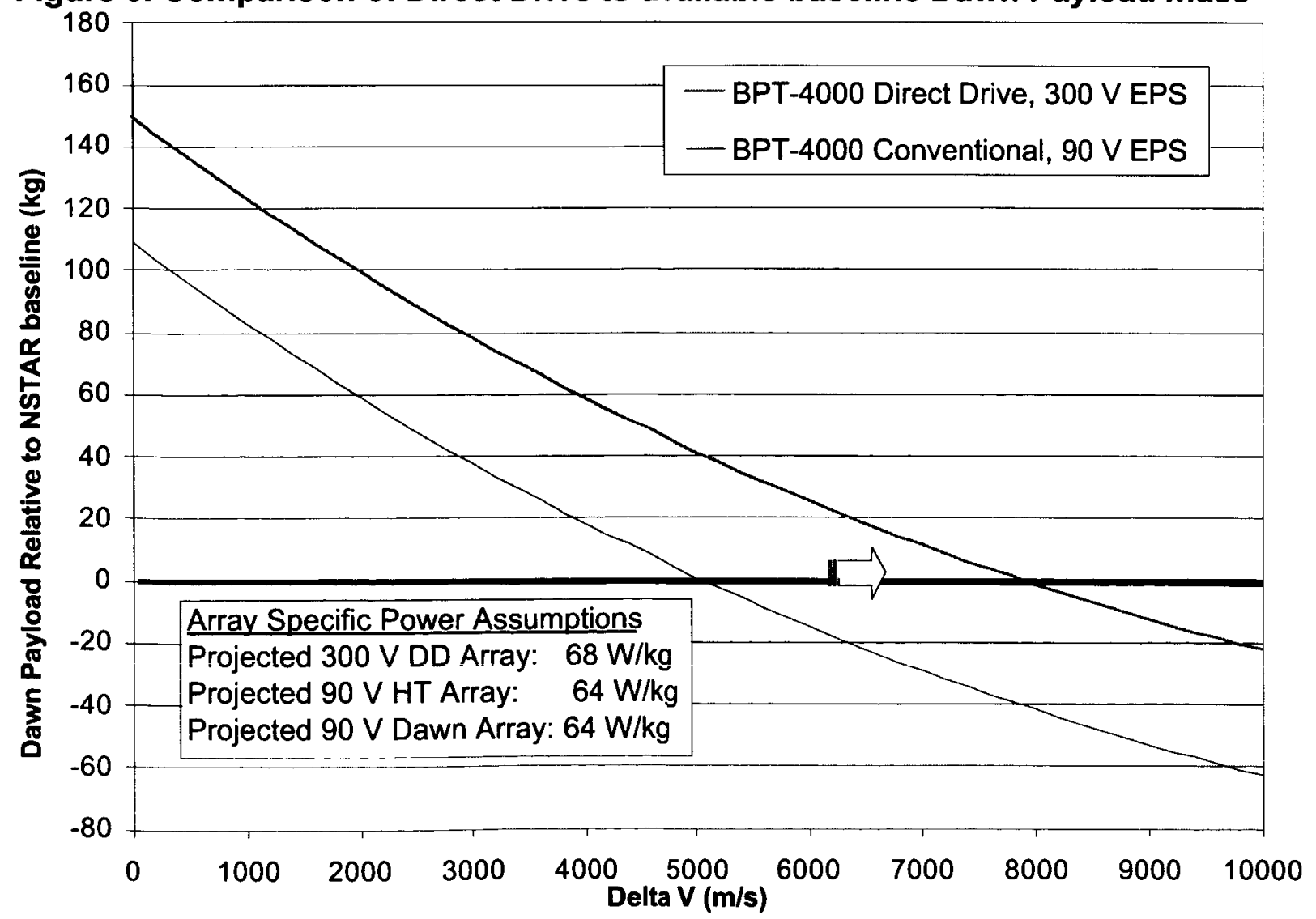


Figure 6. Direct Drive Propulsion Power Unit Reductions

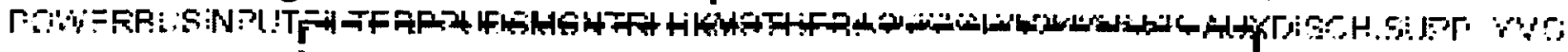

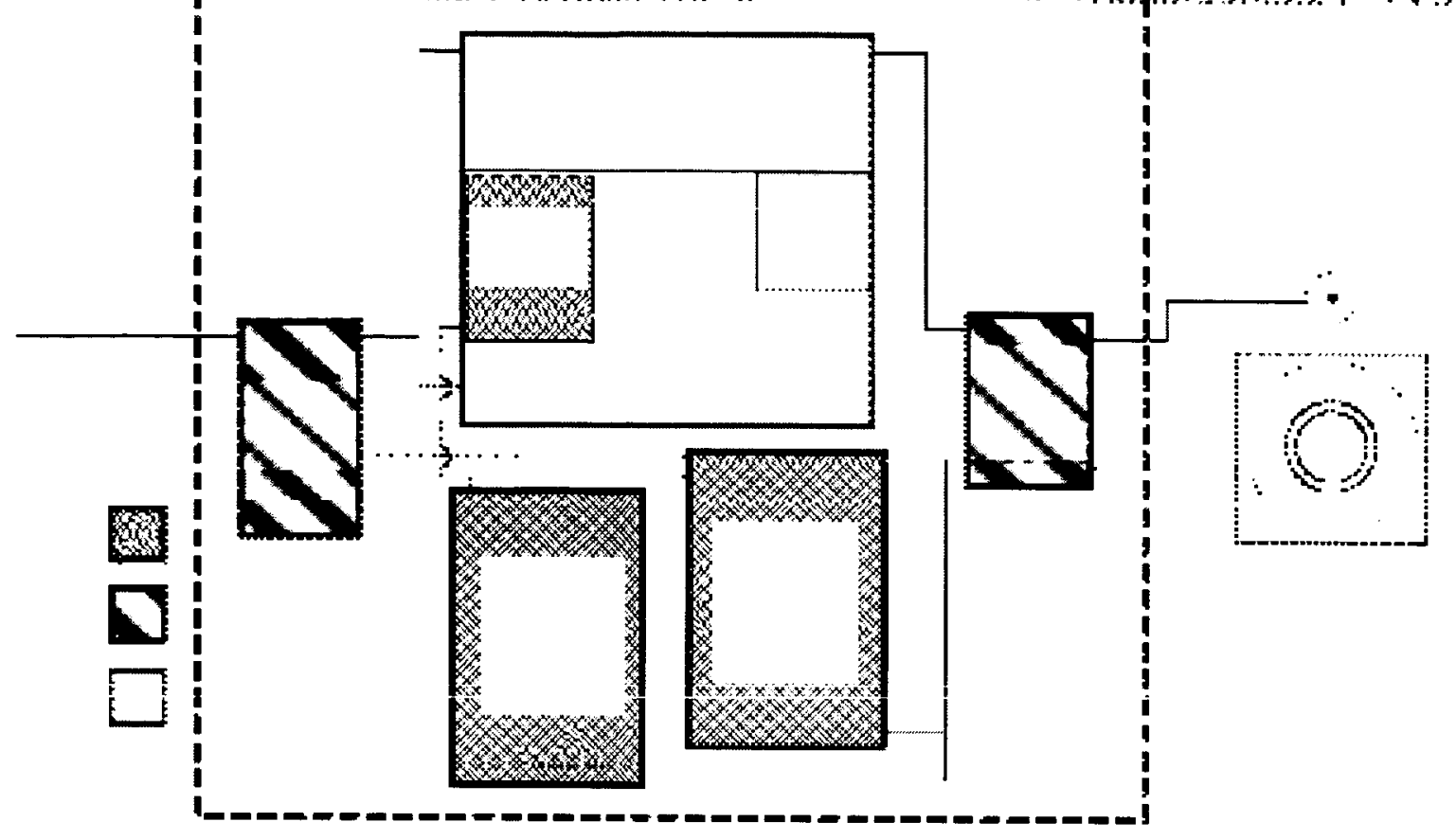

Figure 7. Breadboard Direct Drive PPU System

SOLARARRAYSIMULATOR70 VSUPPLYCOMPUTERRUNNINGLABVIEW

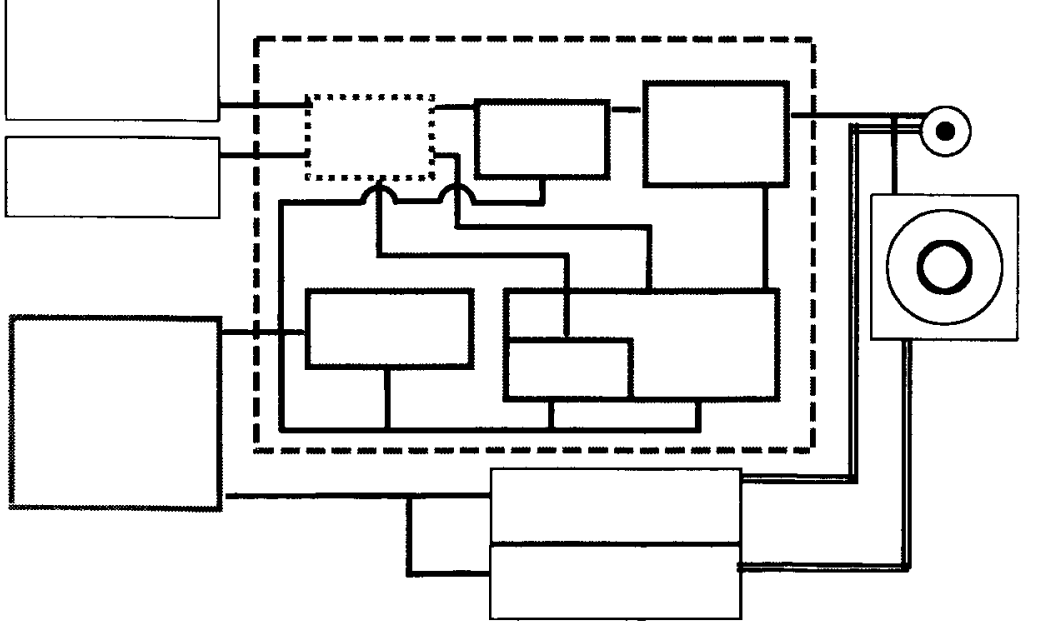

Figure 8. HKM and AUX Circuits

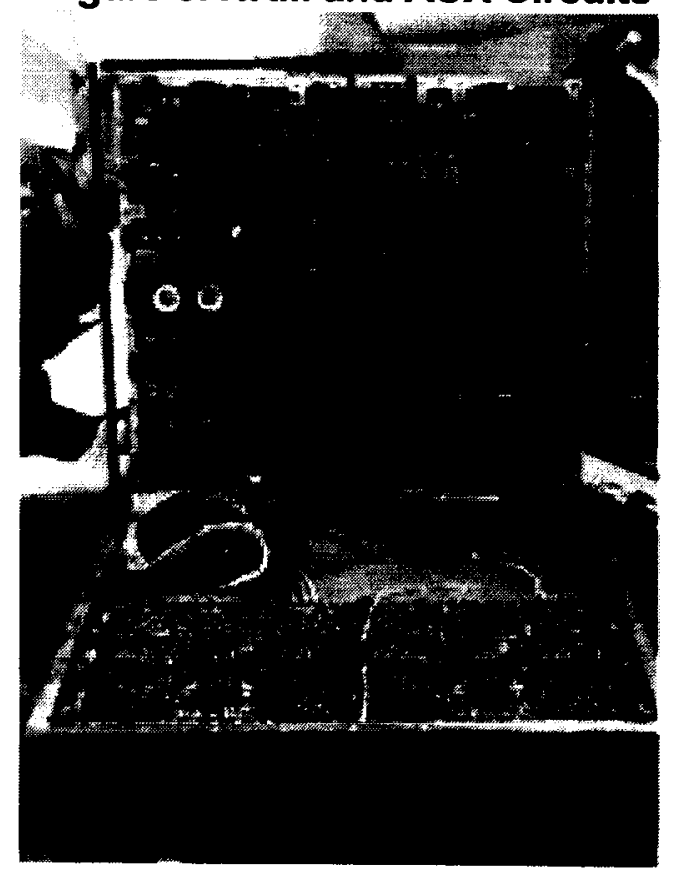

